MATEC Web of Conferences 40, 05009 (2016)

DOI: $10.1051 /$ matecconf/20164005009

(C) Owned by the authors, published by EDP Sciences, 2016

\title{
Experimental research on impact of SCR to diesel buses' emission
}

\author{
Longlin Sun ${ }^{1}$, Wenwei Huang ${ }^{1}$ \\ 1 Shenzhen Polytechnic in Shenzhen City, China
}

\begin{abstract}
The emission experiments of a traditional diesel bus and a SCR diesel bus on a selected expressway in Shenzhen city are carried out with a high-precision mobile emission tester. The experiment data are calculated and the buses' emission characteristics are analyzed. The study shows that the SCR bus $\mathrm{NO}_{\mathrm{X}}$ emission is higher than the traditional diesel bus when the buses' velocity is slow and lower than the traditional one when the velocity is fast. The higher velocity on expressway can help SCR diesel buses increase $\mathrm{NO}_{\mathrm{X}}$ transfer efficiency and reduce $\mathrm{NO}_{\mathrm{x}}$ emission because that the tailpipe exhaust temperature is high when the diesel bus runs fast.
\end{abstract}

\section{Introduction}

The buses in Chinese cities are mostly diesel buses. The data from a famous bus company in Shenzhen city show that the diesel buses account for $83 \%$ of total 3908 buses in this company. The government data show that there are 11170 diesel buses, 580 LNG buses, 1279 pure electric buses and 1771 hybrid electric buses in Shenzhen city until the end of 2014. It means that the diesel buses account for $75 \%$ in this city.

The main harmful components in diesel bus tailpipe exhaust are $\mathrm{NO}_{\mathrm{X}}$ and $\mathrm{PM} . \mathrm{NO}_{\mathrm{X}}$ is toxic and may cause photochemical smog which can lead to vision problem, headache, chest pain and even death. It is more and more urgent to reduce diesel bus $\mathrm{NO}_{\mathrm{X}}$ emission to protect the natural environment and to meet the stricter and stricter emission regulations.

The SCR technology has been utilized for the diesel vehicles to meet stage 4 or 5 national emission standard, especially the heavy diesel buses and trucks. The SCR operational principle is to inject urea and water at a special ratio into diesel vehicle tailpipe exhaust and transfer $\mathrm{NO}_{\mathrm{x}}$ in the tailpipe exhaust into $\mathrm{NH}_{3}$ and water with the help of high exhaust temperature and some special catalysers ${ }^{[1][2][3][4]}$.

\section{Experiment design}

The SEMTECH-DS portable emission analyser is used to measure the $\mathrm{NO}_{\mathrm{x}}$ emission of a SCR diesel bus and a traditional diesel bus on a selected expressway in Shenzhen city. The experiment system is shown as figure 1. The exhaust flow meter (EFM) is used to measure the tailpipe exhaust flow rate and the tailpipe exhaust temperature. A sampling pipe in the EFM samples the tailpipe exhaust and delivers the sample gas to the portable emission analyser to calculate instantaneous $\mathrm{CO}$,
$\mathrm{NO}_{\mathrm{X}}$ and $\mathrm{HC}$ emission rates. The portable emission analyser includes the Nondispersive Infrared Analyzer (NDIR) which measures $\mathrm{CO}$ and $\mathrm{CO}_{2}$, the NonDispersive Ultra-Violet Analyzer (NDUV) which measures the $\mathrm{NO}_{\mathrm{X}}$ and the Heated Flame Ionization Detector (HFID) which measures HC. The temperature hygrometer and the Global Positioning System (GPS) measure the environment temperature/humidity and the vehicle velocity. Then the experiment data are delivered to the portable emission analyser. The PC which connected with the portable emission analyser could zero, calibrate and supervise the experiment system and collect the experiment data.

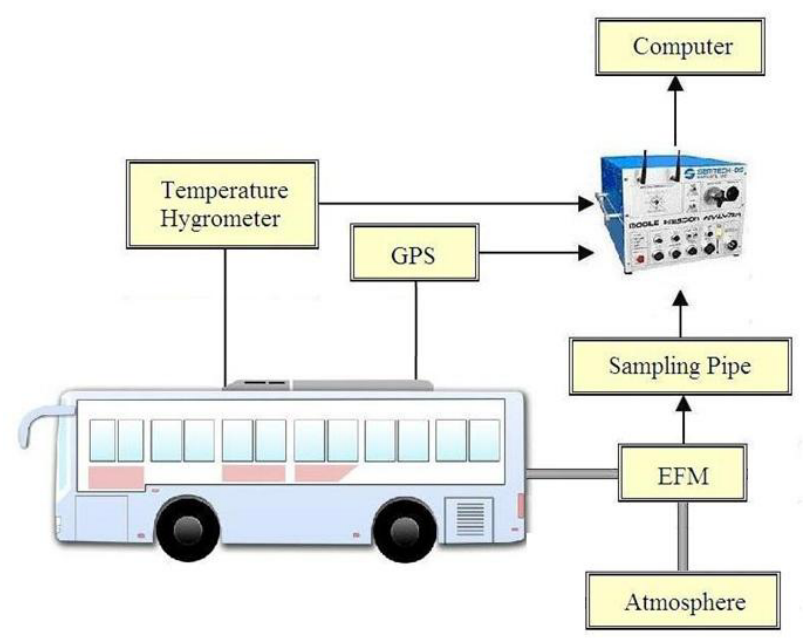

Figure 1. Experiment system sketch diagram.

The experiments are carried out on a typical expressway in Shenzhen city. The selected expressway is the famous beautiful Binhai Road which travels across Nanshan business district, Futian business district and Luohu business district in the south of Shenzhen city. The 
Binhai Road is also near the coastal park and the bird reserve. There are lots of diesel buses run on the Binhai Road and the diesel bus $\mathrm{NO}_{\mathrm{X}}$ emission can affect the health of millions of citizen in this city. The total diesel bus $\mathrm{NO}_{\mathrm{X}}$ emission experimental mileage on the Binhai Road is about $15.5 \mathrm{~km}$.

The selected diesel buses for $\mathrm{NO}_{\mathrm{X}}$ emission experiments are two kinds of familiar diesel buses in Shenzhen city. The traditional diesel bus is manufactured by Yutong Bus Co., Ltd, the most famous bus company in China. The SCR diesel bus is a Higer diesel bus manufactured by Dragon joint Automobile Industry Co., Ltd, another famous bus company in China. The diesel buses' parameters are shown as table 1 .

Table 1. The parameters of two diesel buses.

\begin{tabular}{|c|c|c|}
\hline Type & $\begin{array}{c}\text { Traditional Diesel } \\
\text { Bus }\end{array}$ & SCR Diesel Bus \\
\hline Brand & Yutong & Higer \\
\hline Mileage $(\mathrm{km})$ & 168449 & 167549 \\
\hline Grass Mass(kg) & 16500 & 17000 \\
\hline Length(m) & 11 & 11 \\
\hline Engine Power(kW) & 192 & 191 \\
\hline
\end{tabular}

\section{Experiment result}

The experiments are carried out with an experiment system that is composed of a GPS, an exhaust flow meter and a mobile exhaust analyzer, etc. During the experiment, the traditional diesel bus and the SCR diesel bus are driven by the same driver. The experiment beginning time is also the same. So the interfere of human factor and traffic condition can be minimized as far as possible.

All bus velocity data and instantaneous $\mathrm{NO}_{\mathrm{X}}$ emission rate data are collected by the SEMTECH-DS portable emission analyzer. The velocity data and the instantaneous $\mathrm{NO}_{\mathrm{X}}$ emission rate data of the traditional diesel bus during the whole experiment period are shown in figure 2. The velocity data and the instantaneous $\mathrm{NO}_{\mathrm{X}}$ emission rate data of the SCR diesel bus during the whole experiment period are shown in figure 3 .

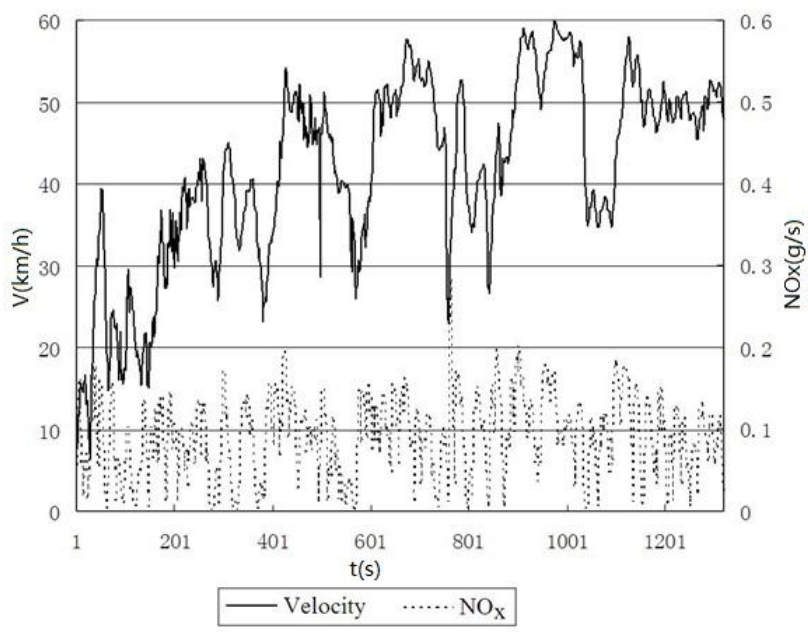

Figure 2. Instantaneous $\mathrm{NO}_{\mathrm{X}}$ emission data of the traditional diesel bus.

The data shows that emission peaks appear mostly in rapid accelerating periods. Some Chinese scholars' research also shows the same rules ${ }^{[5][6][7]}$. NO accounts for $90 \%$ of $\mathrm{NO}_{\mathrm{X}}$ in diesel engine tailpipe exhaust. The high diesel engine temperature will cause NO emission peaks ${ }^{[8]}$. High diesel bus velocity and rapid acceleration may lead to high diesel engine temperature.

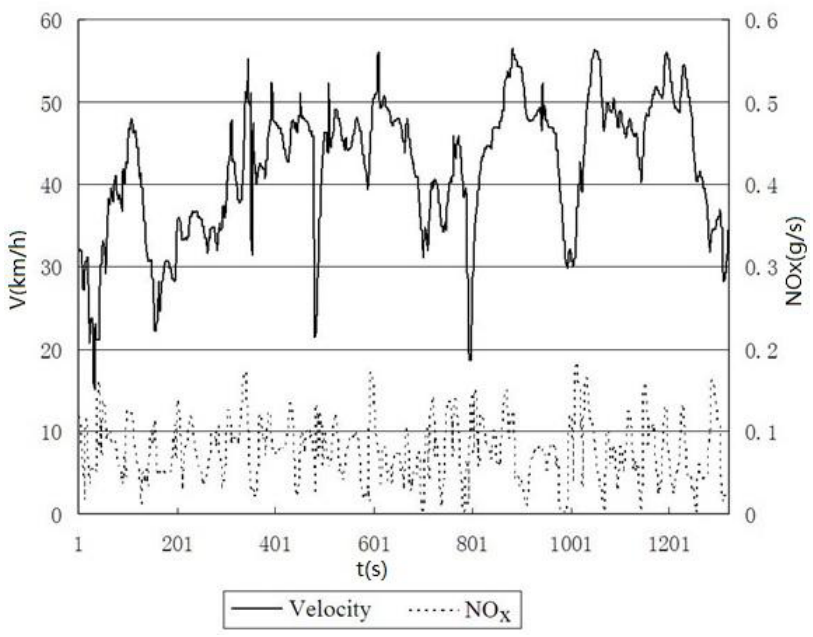

Figure 3. Instantaneous $\mathrm{NO}_{\mathrm{X}}$ emission data of the $\mathrm{SCR}$ diesel bus.

\section{Average emission rate characteristics}

The experiment data are divided into 13 intervals for every $5 \mathrm{~km} / \mathrm{h}$ from $(0,5],(5,10]$ to $(55,60]$. The intervals are named from Q0, Q1 to Q12. The average $\mathrm{NO}_{\mathrm{X}}$ emission rates $(\mathrm{g} / \mathrm{s})$ of the traditional diesel bus and the SCR diesel bus are calculated in every interval. The values of two experiment buses are shown in figure 4 . 


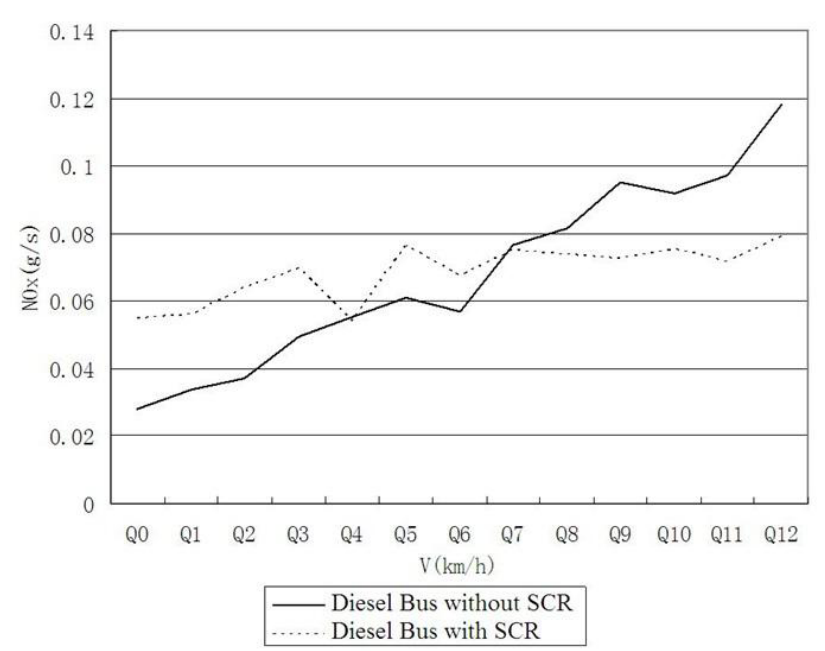

Figure 4. Average $\mathrm{NO}_{\mathrm{x}}$ emission rates of two diesel buses.

Figure 4 shows that average $\mathrm{NO}_{\mathrm{x}}$ emission rates of the traditional diesel bus rise up with the diesel bus velocity due to the rising engine temperature. Average $\mathrm{NO}_{\mathrm{X}}$ emission rates of the SCR diesel bus are higher than the traditional diesel buses when the bus speed is slow and lower than the traditional one when the bus speed is fast. The SCR system efficiency depends on the tailpipe exhaust temperature. When the temperature is rising with the velocity, the catalyser efficiency will rise up and the $\mathrm{NO}_{\mathrm{X}}$ transfer efficiency will be increased and the $\mathrm{NO}_{\mathrm{X}}$ emission will be reduced. The research of a Chinese scholar shows that the $\mathrm{NO}_{\mathrm{x}}$ transferring efficiency will rise up with the diesel bus exhaust temperature when the temperature is beneath $350^{\circ} \mathrm{C}{ }^{[5]}$. The experiment data show that the tailpipe exhaust temperature of two diesel buses is lower than $300{ }^{\circ} \mathrm{C}$ during the whole experiment. So the SCR system efficiency rises up with the velocity during the experiment.

\section{$5 \quad$ Average characteristics}

emission

factor

The experiment data are divided into 13 intervals for every $5 \mathrm{~km} / \mathrm{h}$ from $(0,5],(5,10]$ to $(55,60]$. The intervals are named from Q0, Q1 to Q12. The average $\mathrm{NO}_{\mathrm{X}}$ emission factors $(\mathrm{g} / \mathrm{km})$ of the traditional diesel bus and the SCR diesel bus are calculated in every interval. The values of two experiment diesel buses are shown in figure 5 .

The figure shows the $\mathrm{NO}_{\mathrm{x}}$ emission factors of two diesel buses fall when the speed rises. When the diesel bus velocity is slow, the $\mathrm{NO}_{\mathrm{X}}$ emission factor falls rapid with the velocity. It means that the air quality will be improved when the diesel bus velocity in urban area is high. When the diesel bus velocity is beneath $30 \mathrm{~km} / \mathrm{h}$, average $\mathrm{NO}_{\mathrm{X}}$ emission factors of SCR diesel bus are higher than traditional diesel bus. When the diesel bus velocity is above $35 \mathrm{~km} / \mathrm{h}$, average $\mathrm{NO}_{\mathrm{X}}$ emission factors of SCR diesel bus are lower than traditional diesel bus.

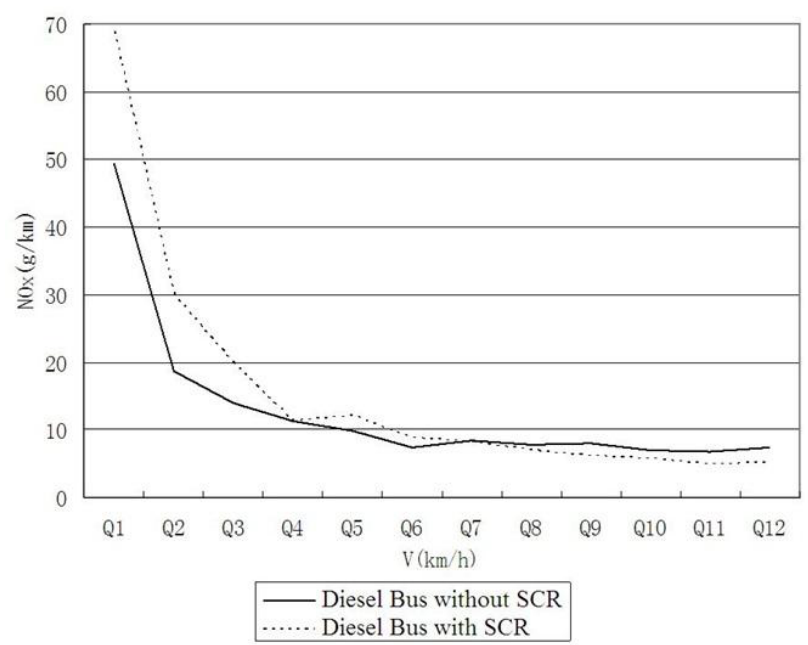

Figure 5. Average $\mathrm{NO}_{\mathrm{X}}$ emission factors of two diesel buses.

\section{Net emission mass}

The net $\mathrm{NO}_{\mathrm{X}}$ emission mass of the traditional diesel bus and the SCR diesel bus are calculated. The net $\mathrm{NO}_{\mathrm{X}}$ emission mass of SCR diesel bus is $94.57 \mathrm{~g}$ and the value of traditional diesel bus is $110.95 \mathrm{~g}$ which is $17.3 \%$ higher than SCR diesel bus. It shows as Figure 6. It means that the SCR system can help reduce $\mathrm{NO}_{\mathrm{X}}$ emission on city expressway.

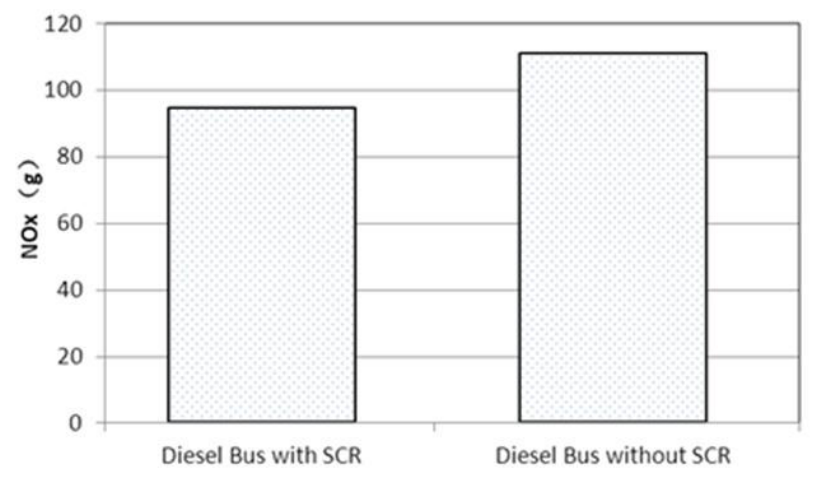

Figure 6. $\mathrm{Net}^{\mathrm{NO}_{\mathrm{X}}}$ emission mass of two diesel buses.

\section{Summary}

The $\mathrm{NO}_{\mathrm{X}}$ emission experiment between a traditional diesel bus and a SCR diesel bus are carried out on city expressway with SEMTECH-DS portable emission analyzer. The experiment system can collect the velocity data, the instantaneous $\mathrm{NO}_{\mathrm{X}}$ emission rate data, the temperature data and the humidity data, etc.

The instantaneous $\mathrm{NO}_{\mathrm{X}}$ emission rate peaks of two diesel buses appear when the diesel bus runs fast or accelerates rapid. The high diesel speed and the rapid acceleration can cause the high diesel engine temperature. The $\mathrm{NO}_{\mathrm{X}}$ emission will increase obvious because of high temperature.

The average $\mathrm{NO}_{\mathrm{X}}$ emission rates of two diesel buses rise with the bus velocity. The average $\mathrm{NO}_{\mathrm{X}}$ emission 
rate of SCR diesel bus is higher than the value of traditional diesel bus when the diesel buses run slow. The average $\mathrm{NO}_{\mathrm{X}}$ emission rate of SCR diesel bus is lower than the value of traditional diesel bus when the diesel buses run fast.

The average $\mathrm{NO}_{\mathrm{X}}$ emission factors of two diesel buses decrease with the bus velocity. The value decreases rapid with the bus velocity when the diesel buses run slow and decreases slow when the buses run fast. It means the high diesel bus velocity can reduce $\mathrm{NO}_{\mathrm{X}}$ emission effectively.

The net $\mathrm{NO}_{\mathrm{X}}$ emission mass of traditional diesel bus is $17.3 \%$ higher than the value of the SCR diesel bus in the whole experiment mileage. The SCR technology can help reduce $\mathrm{NO}_{\mathrm{X}}$ emission on city expressway.

\section{References}

1. Huang, P., "Application Study on SCR Measures in Foreign Vehicular Diesel Engine," Vehicle Engine 3, 5-7 (2005).

2. Li, M. L. and Nie, Y. X., "Study on the Emission Properties of Hybrid Electrical Transit Bus with SCR System," Automobile Technology 3, 34-36 (2010).

3. Gao, J. D., Qin, K. J. and Liang R. L., "An Experimental Study on the PM and NOX Emission Characteristics of Public Bus in Real Driving Condition in Beijing," Automotive Engineering 33(9), 757-760 (2011).

4. Xu, Y. Y., Li, J. H. and Li, M. L., “An Experimental Study on the NOX Emission Characteristics of StateIV City Bus," Automotive Engineering 33(11), 947950 (2011).

5. Li, M. L., Nie, Y. X. and Xu, J. F., "Characters of NOX Emission from Transit Bus with SCR," Journal of Jiangsu University 32(1), 38-42 (2011).

6. Hu, Z. Y., Qin, Y. and Tan, P. Q., "On-road NOX and Ultrafine Particle Emission Characteristics of China IV Diesel Bus in Shanghai," Journal of Tongji University 43(2), 286-292 (2015).

7. Guo, J. D., Ge, Y. S. and Tan, J. W., "A Research on the Real World Emission Characteristics of State-V Buses," Automotive Engineering 37(1), 102-124 (2015).

8. Liu, X. J., [Emission and Control of Internal Combustion Engine], Machinery Industry Press, Beijing, 102-108 (2003). 